\title{
A Qualitative Study of Dysfunctional Behaviours (DB) within a Pakistani Higher Educational Context.
}

\author{
Dr. MUHAMMAD NAWAZ BALOCH \\ Associate Professor, University of Sindh Laar Campus@ Badin. \\ Email: mnawaz@usindh.edu.pk \\ Dr. TAYYABA RAFIQUE MAKHDOOM \\ Assistant Professor, University of Sindh Laar Campus@Badin. \\ Email: tayyaba@usindh.edu.pk \\ Dr. NOOR-UN-NISA SHAHANI \\ Assistant Professor, Bath Spa University, Ras Al-Khaimah, UAE \\ Email: Noor@bathspa.ae
}

\begin{abstract}
The recent development in Pakistani higher educational sector has compelled university management to improve educational service quality. Student dysfunctional behaviours $(S D B)$ is one of the key factors that adversely impacted educational environment. Various researchers have investigated these behaviours in the western context. The objective of this study is to investigate SDB within the Pakistani context. This study used a qualitative approach to develop an in-depth understanding of SDB within Pakistani higher educational context. This current study identified three dimensions of SDB and concluded that understanding of these dimensions will facilitate university management in policy formulation to tackle the issue of $S D B$.
\end{abstract}

Keywords: Student Dysfunctional Behaviours (SDB), University Management, Qualitative Study.

\section{Introduction}

Student dysfunctional behaviour (SDB) is recognised as being responsible for poor academic environments, which negatively impact on other students, the academic and non-academic staff, and thus the academic institution as a whole (Feldmann, 2001; Hirschy and Braxton, 2004; Kearney et al., 2006; Johnson-Bailey, 2014). Therefore, it is essential for university management to understand dimensions of SDB to develop policies to reduce the impact of these behaviours.

Dysfunctional behaviour has been investigated within business contexts. Harris and Reynolds (2003:144) refer to customer dysfunctional behaviour as the: “....actions by customers [students] who intentionally or unintentionally, overtly or covertly, act in a manner that, in some way, disrupts otherwise functional service encounters".

In an educational context, students have shown negative or dysfunctional behaviour due to various reasons. The published literature concerning student negative behaviour mainly concerns the concept of student incivility and student bullying. Feldmann (2001) termed 'incivility' as a behaviour that is harmful to the class environment, and producing a negative impact on the students' learning and instructor's attitude (Kearney et al., 2006). Hirschy and Braxton (2004) also maintain that incivility in the classroom hampers intellectualism in the students and disengages them from class participation. 
Johnson-Bailey (2014) narrates her experience of student bullying during twenty years of academic career, stating that:

"...overall, the uncomfortable encounters with my students can be grouped into two categories: direct and hostile confrontations and passive-aggressive resistance that are uncivil and rise to the level of bullying" (2014:44).

However, she also shares the moments where her students came forward to stop the bullying behaviour of a co-student:

"Fortunately, as the semester continued, and she was relentless in questioning the integrity of my publications and the validity of my abilities, the other students in the class asked her to stop interfering with their learning because they believed I had valuable knowledge to share. In fact, according to one of my journal entries, another student who was very frustrated by her classmate's incessant challenges said, 'How many publications do you have? Okay, none. That is what I figured. So will you shut up so I can learn how to do this from someone who has actually been successful at getting published?' (2014:44)".

One can imagine from this how incivility harms student performance and teachers' commitment to both class and institution.

The only published literature on SDB is reporting on the concept of student incivility, encompassing student negative behaviour within the classroom setting. Various types of dysfunctional behaviour have been identified within the academic context. Some twenty-five negative types of student behaviour have been identified by Bjorklund and Rehling (2009), while Alexander et al. (2009) categorise student negative behaviour into three types: personal uncivil behaviour, collaborative uncivil behaviour and technological uncivil behaviour. Sprunk et al. (2014) report on two major types of student negative behaviour, the first being 'rude and disrespectful' and the second type 'threatening and intimidating', while Goodboy (2011) notes three types of student negative behaviour: expressive dissent, rhetorical dissent and vengeful dissent. Bjorklund and Rehling (2011) note that research in the area of students' uncivil behaviour has primarily focused on the behaviour that students exhibit within a classroom setting. They identify 14 different out of class negative student behaviours, establishing that students can show negative behaviour outside of the classroom.

Sprunk et al. (2014) state that, in a nursing educational context, some students become significantly involved in negative behaviour, harming other faculty members, both socially and psychologically. They conducted a phenomenological study to understand the lived experiences of faculty members while facing student incivility and its impact on nursing faculty members, by conducting twelve interviews with female nursing faculty members.

They report that there are two major types of student uncivil behaviour (rude and disrespectful, threatening and intimidating) and recognise the impact of such rude behaviour on faculty members as being harmful to their health and wellbeing, time-consuming and having a negative impact on the reputation of the teacher, which can increase the possibility of job turnover. However, the study participants did also suggest that positive support from other staff members and from the administration could be helpful in reducing the effects of student negative behaviour.

This study disseminated rich descriptions of these phenomena, through the collective experiences of female nursing students. However, it totally failed to take account of male nursing students. A more comprehensive study would include both male and female nursing students in order to better develop the essence of this incivility phenomena in the context of nursing education. 
Goodboy (2011) conducted a study to explore types of student dissent by collecting data from 123 undergraduate college students. He categorised student dissent into three kinds: (1) expressive dissent, in which students express their anger, (2) rhetorical dissent, where students try to fix the issue, and (3) vengeful dissent, where students act in a way to defame the instructor. The instructor's negative actions were seen as a major source of student dissent, whereby students were also seen to show negative behaviour not only towards the teacher but also towards friends, class fellows and family. Goodboy (ibid.) also developed and validated an instructional dissent scale. Despite the fact that his study provides valuable insights regarding student dissent, further research is needed to check and improve the constructs of the scale. In addition, his study did not take account of any emotional or personality variables while developing his scale.

Myers et al. (2015) use the term 'anti-citizenship behaviours' (ACBs) for students' negative behaviour, defining them as:

“...those verbal and nonverbal behaviors in which students intentionally engage, for whatever reason, that disrupt the flow or function of the classroom environment for either themselves or their classmates" (2015b:236).

Myers et al. (2015) undertook a study to identify the types of ACB and their impact on student learning. To develop their ACB scale, they conducted five focus groups and identified 13 items that were further pilot tested on 250 undergraduate students

In general, the published literature on student incivility encompasses only those negative behaviours displayed by students in the classroom setting. Bjorklund and Rehling (2011) provide evidence that students can show negative behaviour out of class when they interact with teachers beyond the classroom location. They go on to advise students that out of class types of uncivil behaviour could affect the teacher/student relationship, so the student should avoid such behaviour.

\section{SDB in the Context of Pakistan}

Very little is known about SDB in the specific context of higher education in Pakistan. Only a handful of studies are available in the published research literature. Iqbal (2004) points out that the purpose of a university is to develop human resources (people) with particular intellectual and professional capacities. Based on his study, he suggests that a university's administration should work towards the character building of their students. To achieve this, we need to have a clear understanding of the dynamics of dysfunctional behaviour, so that we have a clear picture to fully develop our understanding of these phenomena.

Munawar et al. (2014) conducted a study to ascertain the dynamics of cyber bullying within the context of higher education in Pakistan. The study sample consisted of 100 university students. Their report states that $77 \%$ of these students are regular users of 'Facebook', 89\% owned a mobile telephone and $15 \%$ had 'Twitter' accounts. The study recognises that the majority of these students use social networking sites to interact with family, friends and acquaintances, whereas only 3\% interacted with 'Stranger'. The study identifies the major types of cyber bullying (e.g., online humiliating post, computer text messages sent to harass, posting a picture without your permission, telephone call to harass). The study further highlights that immediate group fellows, peer group, known persons and unknown persons are the main sources of these bullying practices. They argue that cyber bullying may be directly affecting educational development, and causing emotional imbalance and psychological issues amongst students.

Similarly, Avais et al. (2014) conducted a study to understand cyber bullying in the context of the University of Sindh, in Jamshoro, Pakistan (UOSJP). Their study shows that the majority of the students are frequent users of internet services and that they are aware of cyber bullying. The study also reports that 
the majority of the participants have been victims of cyber bullying of various types at some time, such as hacking, impersonation, and/or receiving defamatory or hate messages. The study also recognises that female students are more likely to be subjected to cyber bullying. Interestingly, they report that $30 \%$ of these victims stated that they knew the propagators responsible for their cyber bullying. Another study, conducted by Gulzar et al. (2012) to examine the causes of frustration among university students, collected data from 120 university students. They report that although bullying is one of the contributors to student frustration, it does not have any significant value.

Kashif et al. (2013) conducted a study to analyse negative behaviour among university students, using a mixed-method approach, by gathering data from 350 students, 50 faculty members and 45 parents of students at two public sector universities. The study reported that substance usage, cheating, harassment, bullying, property destruction and joyriding are major dimensions of student negative behaviour. However, their study investigated student anti-social behaviour in the context of student politics. The researchers included some photographs as evidence for student anti-social behaviour, but the authenticity of these pictures is questionable as it seems that the researchers used images obtained from social media to support the findings of their study.

\section{Objective of research}

In summary, if we look at previous studies, it can be seen that there have not been any detailed investigations carried out into SDB. In addition, previous research (for example, Avais et al., 2014; Munawar et al., 2014) conducted within the Pakistani higher education context have employed small surveys, limited methodological rigour and covered only limited dimensions of the phenomenon. Moreover, research within the global context has been primarily focused on the in-class negative behaviour of students, with the researchers ignoring out of class dysfunctional behaviour. It is thus important to further explore dysfunctional behaviour, and how students participate in dysfunctional behaviour within the context of higher education in Pakistan.

\section{Research Methodology}

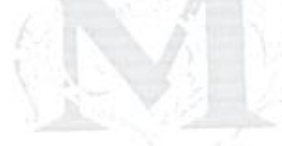

The interpretative phenomenological approach has been used to examine SDB in Pakistani higher educational context. Furthermore, the cross-sectional research design was adopted to collect data via semistructured in-depth interviews and focus groups simultaneously. Before conducting this research ethical approval was taken. Furthermore, the research participant information sheet was prepared and distributed among the participants. Moreover, research consent forms signed by all participant. Five small size focus groups and twenty semi-structured interviews were conducted from senior students of the University of Sindh, Jamshoro, Pakistan (UOSJP) to achieve saturation level. UOSJP is the second oldest university of Pakistan and suitable place to access homogeneous sample. In addition, senior students were experiencing phenomena under study better then freshers. Participants were selected through purposive random sampling and snowball random sampling techniques. Keeping in mind ethical consideration location of focus group and interviews were decided with the consent of participants and during interviews, female participants were allowed the presence of family member or friend as per Pakistani cultural values. The data analysis process was guided by the hermeneutical phenomenological approach.

\section{Discussion}

The data analysis identified three types of dysfunctional behaviour in the surveyed students which disturb the effective service delivery process in an academic setting, i.e., communication-related SDB, actionrelated SDB and public property-related SDB. 


\section{Communication-related SDB}

Communication-related SDB refers to those negative types of behaviour which students have shown by mean of communication (verbal and non-verbal, online and offline). The first sub-theme of communication-related SDB is appearance and dressing style. The findings of this current study report appearance and dressing style as one form of non-verbal communication, whereby expensive dresses and other expensive items (such as watches, mobiles, jewellery) used by students develop frustration among costudents. Due to economic and religious reasons, the study participants felt that students should not use a modern dressing style, so that their co-students do not feel inferior or so as not to cause any harm to their religious feelings.

Boice (1996) found that wearing inappropriate clothing is non-serious uncivil behaviour, and current study concurs with this finding. In addition, Bjorklund and Rehling (2011) identify revealing dressing as a SDB in the American academic context. However, it seems that appearance and dressing style is a significant SDB due to cultural, religious and economic reasons in the context of Pakistani higher education.

The second sub-theme of communication-related SDB refers to passing comments. The study participants frequently discussed that many students passed negative comments on the presentation style and the dressing style of other students at the university. In addition, the study participants considered it disturbing and disrespectful. A survey conducted by Ulrich et al. (2006) involving critical care nurses indicated that $24.1 \%$ of these nurses said that their colleagues or managers used disrespectful language towards them. This current study results match those of Ulrich et al., in that students at UOSJP are subject to verbal abuse from other students, which affects the academic performance of these students.

The third sub-theme of communication-related SDB is the use of electronic devices in the classrooms and outside of the class. This study found that the participants observed that the frequent use of modern mobiles and tablets is disturbing to co-students, teachers and members of staff. Berger (2000) terms the use of mobiles and computers as passive incivility. However, findings show that, in the context UOSJP, it is not passive at all, because it has been actively used by students at various locations to disturb others. These findings match with the studies of Bjorklund and Rehling (2009) and Alexander et al. (2009), who reported on technology-related SDB.

The fourth sub-theme of communication-related SDB is the calling of others by a shortened name. The study participants claim that, within Pakistani culture, it is inappropriate to call a person by a shortened name or speak to staff and teachers without adding 'Sir' or 'Madam'. Moreover, students who practise this behaviour create anger among staff and faculty members. Heinemann (1996) describes that often in the workplace people will replace another person's name with an animal name, terming it as a dehumanisation of the name. However, in the context of UOSJP, participants did not report dehumanisation, but they did consider that replacing the full name or not using 'Sir' or 'Madam' was disrespectful behaviour.

The fifth sub-theme of communication-related SDB is asking too many irrelevant questions. The findings of this study show that a few students, due to various reasons, would always ask too many irrelevant questions from the teacher during lectures. These questions disturb the teacher and the class, and due to this, the teacher will become angry. Feldmann (2001) considers that asking too many irrelevant questions is a major threat in the service delivery process, discussing it under the theme of 'classroom terrorism'.

The sixth sub-theme of communication-related SDB is the negative oral and electronic campaign observed at UOSJP. The study results mention that students have been involved in spreading negative word of mouth and electronic communications aimed towards the staff, faculty members and institution. Berry and Seiders (2008) identify such customers, in the business context, as 'blamers' - a category of unfair customers. Findings of this study are in agreement with Goodboy (2011), who terms such behaviour as a 'vengeful dissent' in the academic context. In vengeful dissent, unsatisfied students begin to defame others to take 
revenge. Findings of this research suggest that, in the context of UOSJP, students (due to genuine or ungenuine reasons) are blaming others by both offline and online means of communication.

The seventh sub-theme of communication-related SDB is calling external media onto the campus. The study participants reveal that students who experience some grievance and have a connection with the media will sometimes call the media onto the campus. It provides the local newspaper or news channel with an opportunity to portray a negative university image. This finding was unexpected and suggests that some students can go beyond traditional types of dysfunctional behaviour. It seems that, in the context of UOSJP, students can use any tactic that could harm the university's reputation and could put pressure on the administration.

\section{Action-related SDB}

The first sub-theme of this is physical aggression. The data analysis shows that students have shown physical aggression towards other students, the staff and faculty members on various occasions. This finding is consistent with the findings of Harris and Reynolds (2003), who term such individuals as physical abusers. In addition, findings of this current study also match with Feldmann (2001) who describes physical aggression as high-intensity uncivil behaviour in the educational context.

The second sub-theme of action-related SDB is where students do not follow instructions. The findings of this study reveal that students are not observing standard procedures or norms during the service delivery process, both in the class and out of the class. Fullerton and Punj (2004) note that customers' wilful disobedience is one type of dysfunctional behaviour towards frontline staff in the business context. In addition, Lovelock (1994) terms such customers as 'rule breakers'. Feldmann (2001) describes this as lowintensity uncivil behaviour, in which students do not maintain the normal decorum within the classroom. These results match with those of Bjorklund and Rehling (2009), who consider not following instructions as a student negative behaviour.

The third sub-theme of action-related SDB refers to arriving late and leaving class early. The data analysis shows that some students intentionally arrive late and leave the class early to disturb faculty members during the service delivery process. A study conducted by Attwood (2009) to understand student destructive behaviour in the UK found that $91.4 \%$ of students came late to the class and $85 \%$ had the intention to leave the class early. Clark et al. (2010) also support this in the Chinese context, where $60 \%$ of students arrive late in the class. Bjorklund and Rehling (2009) report early and late arrival in the class as dysfunctional behaviour. It seems that students often use this behaviour as a tactic to disturb faculty members and the service delivery process.

The fourth sub-theme is showing fake attention. The findings of this study report upon the ways by which students give an impression to the faculty member that they are hearing and paying attention to the teacher. However, during this time, the students are doing work of their interest such as playing games or listening to music. Okubo et al. (2012) conducted a study to identify types of facial expressions from pictures of models who posed for fake angry and happy expressions. Sixty-eight undergraduate students participated in the study. It was found that fake people displayed more smiles, showing that these participants were not able to judge fake behaviour. In addition, Bjorklund and Rehling (2009) found that fake attention is one type of student negative behaviour demonstrated in the classroom setting.

The fifth sub-theme refers to ghost students. The study participants reveal that many students do not attend their classes. However, a friend is used to sign the attendance sheet for them. Nilson and Jackson (2004) report that universities with large class sizes provide a conducive environment for students to do such things, without it coming to the notice of a faculty member. It can thus be suggested that students are taking advantage of the traditional method of attendance recording and large class sizes at UOSJP to disguise their 
actions in favour of their absent friend. However, such behaviour is not beneficial for either their costudents or the institution.

The sixth sub-theme refers to self-granted leave. The data analysis shows that students had been seen to take self-granted leave at UOSJP. Self-granted leave is a phenomenon whereby the majority of students in a class join together to decide not to attend classes for a specific period. In addition, these students report financial, health, social and emotional justification for this self-granted leave. However, the study participants did admit that somehow it disturbs their academic performance. A study conducted by Bashir et al. (2012) to explore employees' counterproductive behaviour in a Pakistani public sector organisation found that $69 \%$ of employees wilfully remained absent. However, in the context of UOSJP, that wilful decision is based on the collective consent of the students, albeit that it was harming both the students' and institution's performance.

\section{Public Property-related SDB}

The third super-theme is public property-related SDB. The data analysis shows that students adopt various means to destroy the public property of the university and also misuse common facilities.

The first sub-theme of public property-related SDB involves graffiti. The study participants shared that students have drawn pictures, messages and political slogans on various places (corridors, walls, toilets and in the hostels). This significantly affects the appearance of the university's buildings. In addition, it communicates a negative impression to both students and visitors. Farnia (2014) reports that graffiti is considered illegal in many places, as it damages property. She found, in her study in the Iranian context, that graffiti is used by Iranian students to show love and hate, to express the students' voice, to spread political ideology and to complain. This is an important issue for future research, so as to understand why students use graffiti in the context of UOSJP. However, this study found that graffiti has damaged the physical appearance of UOSJP.

The second sub-theme of public property-related SDB is the misuse of common facilities. This current study reports that students often misuse common facilities such as the library, computer laboratory, university-owned buses and campus accommodation. Bashir et al. (2012) report that the frequency of misuse of organisational resources is $49 \%$ among public sector staff in another Pakistani context. A possible explanation for this might be that students within the academic setting have followed the same trend, and it may be an effect of the social system.

The third sub-theme concerns property destruction. The study participants claim that some students destroy or cause damage to university property. Harris and Reynolds (2003) term customers who destroy, steal and misuse the organisation's property as 'property abusers' in the business context. Bashir et al. (2012) report that the frequency of damaging public property is $38 \%$ and the wasting of resources is $72 \%$ among public sector employees in the Pakistani context. Kashif et al. (2013) report that property destruction is a major anti-social behaviour of university students in Pakistan.

\section{Conclusion}

This research explored how students display dysfunctional behaviour within the specific context of Pakistani public higher education. Prior studies (such as Alexander et al., 2009; Bjorklund and Rehling, 2009; Sprunk et al., 2014) have identified various forms of SDB in the Western context. This study has now reported upon three types of SDB seen within the Pakistani academic setting, being those of communication-related dysfunctional behaviour, action-related dysfunctional behaviour, and public property-related dysfunctional behaviour. 
Some of these results match those observed from earlier studies in the academic context (particularly, those of Alexander et al., 2009: Bjorklund and Rehling, 2009; Sprunk et al., 2014). However, this study found some distinctive dysfunctional behaviours within the specific context of Pakistani public higher education which are different from those previously reported, such as displays of fake attention, calling external media onto the campus, virtual campaigns against the institution, faculty and staff members, and group coordinated self-granted leave. Furthermore, this study has identified that students not only display dysfunctional behaviour within the classroom setting, but this phenomenon also exists outside of the classroom.

\section{Recommendations}

The findings of this study reported that ethnic and religious orientation of students could contribute to SDB. This suggests that there is a need for a student counselling service at UOSJP, which may help prevent or reverse many instances of SDB. It is further suggested that the student-counselling service hire those individuals, who know the context of higher educational institutions, macro-social, political, religious and cultural environment.

The findings of this current study suggested that more and improved participation options should be made available to the students at UOSJP, so that this could develop improved affiliation and feelings of ownership among the students. A key policy priority should be to develop a new and modified student union system, which would better fit with the requirements of the time. Not only would this help in developing a civic sense amongst the students, but it would also provide an opportunity for selected students to participate in the matters of university management, acting as a major stakeholder. Obiero (2012) maintains that student participation in university management, through the student union, develops a sense of attachment among students and reduces the possibilities of student negative behaviour.

\section{Recommendations for Further Research Work}

This research has put forward many questions in need of further investigation. What is now needed is a cross-sectional study involving staff, faculty members and department heads in order to holistically understand their experiences of SDB, to obtain a more comprehensive understanding.

\section{References}

Alexander, M.W., Mundrake, G.A. \& Brown, B.J. (2009). Pre business college freshman perception of classroom behaviour: an analysis among and between genders. The Journal of Research in Business Education, 51(2), 99-116.

Attwood, R. (2009). .Mind your manners, not the phone, please. Times Higher Education

Avais, M. A., Wassan, A., Narejo, H., \& Khan, J. (2014). Awareness regarding cyber victimization among students of University of Sindh, Jamshoro. International Journal of Asian Social Science, 4(5), 632641.

Bashir, S., Nasir, M., Qayyum, S., \& Bashir, A. (2012). Dimensionality of Counterproductive Work Behaviors in Public Sector Organizations of Pakistan. Public Organization Review, 12(4), 357-366. doi:10.1007/s11115-012-0177-8

Berry, L.L. \& Seiders, K. (2008). Serving unfair customers. Business Horizons, 51(1), 29-37. https://doi.org/10.1016/j.bushor.2007.09.002

Bjorklund, W., \& Rehling, D. (2011). Incivility Beyond the Classroom Walls. InSight: A Journal of Scholarly Teaching, 6, 28-36. doi:10.46504/06201102bj

Bjorklund, W.L. \& Rehling, D.L. (2009). Student perceptions of classroom incivility. College Teaching, 58(1), 15-18. https://doi.org/10.1080/87567550903252801

Boice, B. (1996). Classroom incivilities. Research in Higher Education, 37(4), 453-486. https://doi.org/10.1007/bf01730110 
Clark, C.M., Otterness, N., Jun, W.Y, Allerton, B., Black, M., Juan, C.M. \& Wei, F. (2010). Descriptive study of student incivility in the People's Republic of China. Journal of Cultural Diversity, 17, 136150 .

Farnia, M. (2014). A thematic analysis of graffiti on the university classroom walls - a case of Iran. International Journal of Applied Linguistics and English Literature, 3(3), 48-57. https://doi.org/10.7575/aiac.ijalel.v.3n.3p.48

Feldmann, L.J. (2001). Classroom civility is another of our instructor responsibilities. College Teaching, 49(4), 137-140. https://doi.org/10.1080/87567555.2001.10844595

Gulzar, S., Yahya, F., Nauman, M., Mir, Z. \& Mujahid, S.H. (2012). Frustration among university students in Pakistan. International Research Journal of Social Sciences, 1(4), 7-15.

Harris, L.C. \& Reynolds, K.L. (2003). The consequences of dysfunctional customer behaviour. Journal of Service Research, 6(2), 144-161. https://doi.org/10.1177/1094670503257044

Heinemann, R.L. (1996). Addressing campus-wide communication incivility in the basic course: a case study. Paper presented at the Annual Meeting of the Speech Communication Association, $82^{\text {nd }}$, San Diago, California, 23-26 November.

Hirschy, A.S. \& Braxton, J.M. (2004). Effects of student classroom incivilities on students. New Directions for Teaching and Learning, 99, 67-76. https://doi.org/10.1002/t1.160

Iqbal, A. (2004). Problems and prospects of higher education in Pakistan. Doctoral thesis, PMAS-Arid Agriculture University, Rawalpindi, Pakistan.

Johnson-Bailey, J. (2014). Academic incivility and bullying as a gendered and racialized phenomena. Adult Learning, 26(1), 42-47. https://doi.org/10.1177/1045159514558414

Kashif, N.U., Ali, A. \& Kelly, T.B. (2013). Perceptions and practices of social behaviors among university students in Pakistan. Far East Journal of Psychology and Business, 10(5), 59-73.

Kearney, P., Plax, T.G. \& McPherson, M.B. (2006). Student incivility and resistance in the classroom. In: T. Mottet, V. Richmond \& J. McCroskey, J. (eds.) (2006). Handbook of Instructional Communication: Rhetorical and Relational Perspectives, New York: Taylor \& Francis, pp.235-251.

Lovelock, C.H. (1994). Product plus: how product service = competitive advantage. European Management Journal, 12(2), 240-241.

Munawar, R., Inam-ul-haq, M.A., Ali, S. \& Maqsood, H. (2014). Incidence, nature and impacts of cyber bullying on the social life of university students. World Applied Sciences Journal, 30(7), 827-830.

Myers, S.A., Goldman, Z.W., Ball, H., Carton, S.T., Atkinson, J., Tindage, M.F. \& Anderson, A.O. (2015). Assessing college student use of anti-citizenship classroom behavior: types, reasons, and association with learning outcomes. Communication Teacher, 29(4), 234-251. https://doi.org/10.1080/17404622.2015.1064984

Nilson, L. \& Jackson, N. (eds.) (2004). Fourth Conference of the International Consortium for Educational Development, Ottawa, Ontario, proceedings, Ottawa, Ontario: International Consortium for Educational Development.

Okubo, M., Kobayashi, A. \& Ishikawa, K. (2012). A fake smile thwarts cheater detection. Journal of Nonverbal Behavior, 36(3), 217-225. https://doi.org/10.1007/s10919-012-0134-9

Sprunk, E.A., LaSala, K.B. \& Wilson, V.L. (2014). Student incivility: nursing faculty lived experience. Journal of Nursing Education and Practice, 4(9), 1-12. https://doi.org/10.5430/jnep.v4n9p1

Ulrich, B.T., Lavendaro, R, Hart, K.A., Woods, D., Leggett, J. \& Taylor, D. (2006). Critical care nurses' work environments: a baseline status report. Critical Care Nurse, 26(5), 46-57. https://doi.org/10.4037/ccn2006.26.5.46 